\title{
EFFECT OF RESIDUAL STRAIN ON ALPHA CR PRECIPITATION IN ALLOY 718 FASTENERS
}

\author{
John F. Radavich ${ }^{1}$ and Bruce Lindsley ${ }^{2}$ \\ ${ }^{1}$ Micromet, West Lafayette, IN \\ ${ }^{2}$ Special Metals Corporation, New Hartford, NY
}

\begin{abstract}
Alloy 718 is typically used as a fastener material where high strength, corrosion resistance, and elevated temperature service are critical requirements. At elevated temperatures, the precipitation of alpha $\mathrm{Cr}$ phase in grain boundaries of alloy 718 can markedly decrease its impact properties. Increased amounts of residual strain in the material dramatically increase alpha $\mathrm{Cr}$ precipitation and growth. $1517 \mathrm{Mpa}$ (220 ksi) bolts, which are made from $20 \%$ cold worked bar, were found to have more alpha $\mathrm{Cr}$ than $1241 \mathrm{Mpa}(180 \mathrm{ksi})$ bolts both before and after high temperature exposure. Experiments on the $20 \%$ cold worked bar revealed that the alpha $\mathrm{Cr}$ precipitated during the $718^{\circ} \mathrm{C}$ part of the direct aging cycle and that a solution treatment of $982^{\circ} \mathrm{C}$ did not decrease the precipitation. When alloy 718 bolts were exposed at $538^{\circ} \mathrm{C}$ for 500 hours, severe alpha $\mathrm{Cr}$ precipitation occurred adjacent to the cold rolled bolt threads, where alpha $\mathrm{Cr}$ was found in a fine network of either grain or subgrain boundaries.
\end{abstract}




\section{Introduction}

The versatility of alloy 718 is evidenced by its widespread use in castings and forgings employed by the aerospace, gas turbine, and chemical industries. Alloy 718 is currently used as a fastener material where corrosion resistance and strength are prime requirements. Roach describes the current fastener materials and the factors used for selection of alloy 718 as a fastener material (1). Alloy 718 fasteners are used for applications where minimum tensile strength requirements are $1241 \mathrm{MPa}(180 \mathrm{ksi})$ and $1517 \mathrm{MPa}(220 \mathrm{ksi})$. The $1241 \mathrm{MPa}$ tensile strengths are achieved by standard solution and aging techniques, while the $1517 \mathrm{MPa}$ strengths are obtained by direct aging after approximately $20 \%$ cold work. Direct age parts do not undergo a solutioning step and typical aging cycle temperatures are $718^{\circ} \mathrm{C}\left(1325^{\circ} \mathrm{F}\right)$ followed by $621^{\circ} \mathrm{C}\left(1150^{\circ} \mathrm{F}\right)$. As the amount of cold work increases, the ultimate tensile strength increases, and as shown by Roach (1), alloy 718 fasteners experience a severe drop in ductility below a critical level as the ultimate tensile strength exceeds $1655 \mathrm{MPa}(240 \mathrm{ksi})$.

In long time studies of alloy 718 in a temperature range of $593^{\circ} \mathrm{C}\left(1100^{\circ} \mathrm{F}\right)$ to $760^{\circ} \mathrm{C}\left(1400^{\circ} \mathrm{F}\right)$, it was found that alpha $\mathrm{Cr}$ phase forms associated with the delta phase. At $593^{\circ} \mathrm{C}$, the alpha $\mathrm{Cr}$ phase appears without obvious changes in either the $\gamma^{\prime \prime} / \gamma^{\prime}$ precipitation or the strength properties, but the impact properties are lowered(2). Recent studies of direct aged alloy 718 forgings has shown that the residual strain in the forgings enhance the formation of the alpha $\operatorname{Cr}(3)$. In addition, it has been shown that cold working alloy 718 greatly increases the kinetics of alpha $\mathrm{Cr}$ growth(4). It is believed that the precipitation and growth of the alpha $\mathrm{Cr}$ phase in conjunction with the delta phase in severely worked alloy 718 grain boundaries degrades ductility and impact resistance and is the focus of this study.

\section{Experimental Procedure}

The sample preparation techniques used for this alloy 718 bolt study were the same as described previously to detect the alpha $\mathrm{Cr}$ phase(2-4). The alpha $\mathrm{Cr}$ phase can be etched out by an electrolytic polish followed by an electrolytic etch in a chromate based solution. This etch preferentially etches chromium rich phases. Electropolishing alone will reveal the alpha $\mathrm{Cr}$ in relief, but the contrast is low and it can be difficult to distinguish the alpha $\mathrm{Cr}$ and the delta phase. X-ray diffraction on extracted residues was used to verify that the etched out phase is alpha $\mathrm{Cr}$.

A large number of alloy 718 bolts have been structurally evaluated to understand their mechanical performance. Bolt microstructure was examined in the as-received condition and after exposure at $538^{\circ} \mathrm{C}\left(1000^{\circ} \mathrm{F}\right), 649^{\circ} \mathrm{C}\left(1200^{\circ} \mathrm{F}\right)$ and $677^{\circ} \mathrm{C}\left(1250^{\circ} \mathrm{F}\right)$ for extended times. The tendency to form the alpha $\mathrm{Cr}$ in such tests is a good indicator of the longer time behavior of alloy 718. Bolts with minimum tensile strengths of $1241 \mathrm{MPa}(180 \mathrm{ksi})$ and $1517 \mathrm{MPa}(220 \mathrm{ksi})$ were studied. All bolts originated for a single bolt supplier. A sample of $20 \%$ cold work bar was also supplied by the manufacturer.

\section{Results}

\section{As-Received Microstructures}

It was found that the alloy 718 used for bolts exhibited large variations in grain size and in the amount and shape of the delta phase. Figure 1 shows two examples of delta phase morphology present in bolts. The variations in microstructure and grain size can be related to the processing prior to the bolt manufacture. Several bolts were examined for alpha $\mathrm{Cr}$ in the as-received condition. This was done to provide a starting microstructure and it was expected that no alpha 

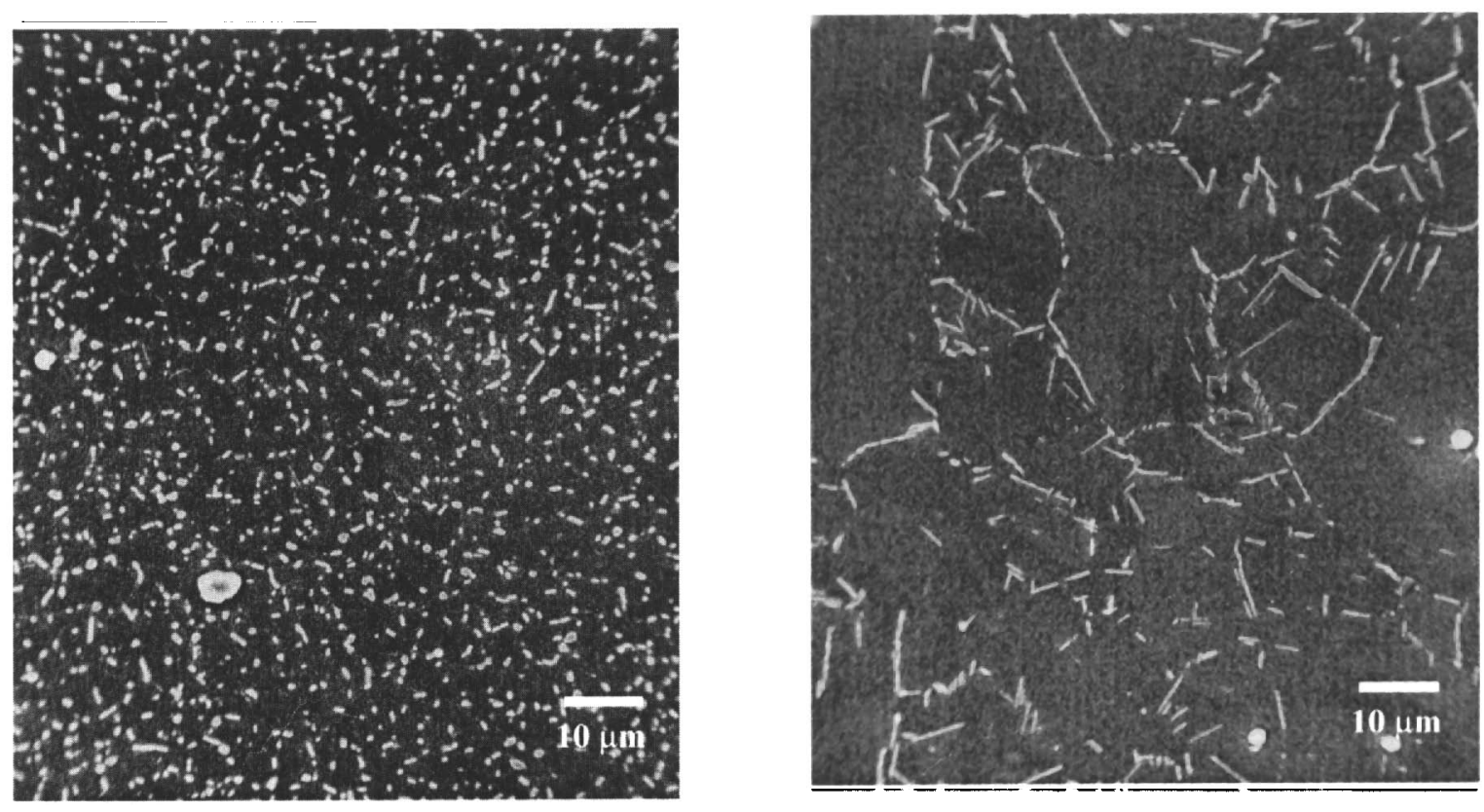

Figure 1. Examples of cross-sectioned bolts showing the variable starting microstructures.

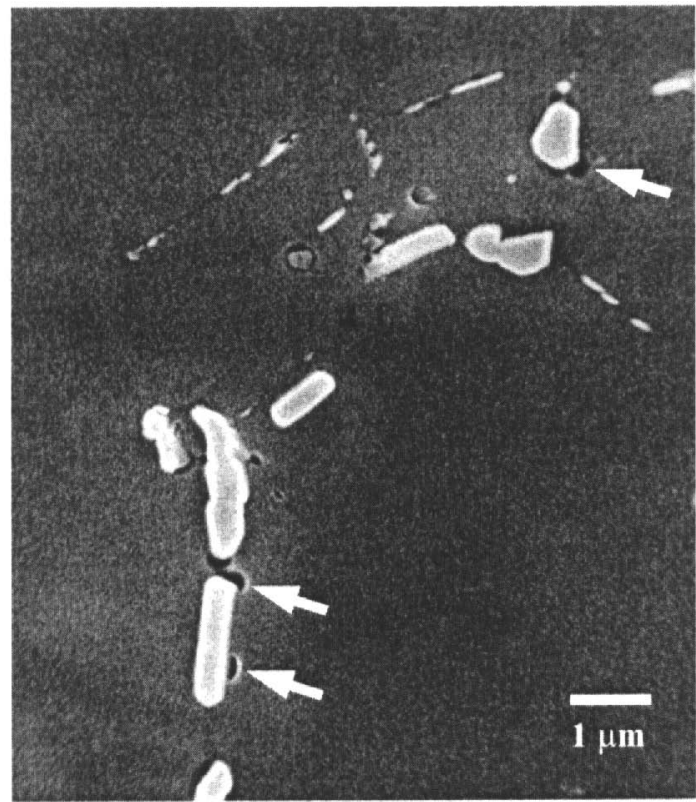

Figure 2. As-received bolt microstructure showing the presence of alpha $\mathrm{Cr}$ (arrows mark the etched out holes).

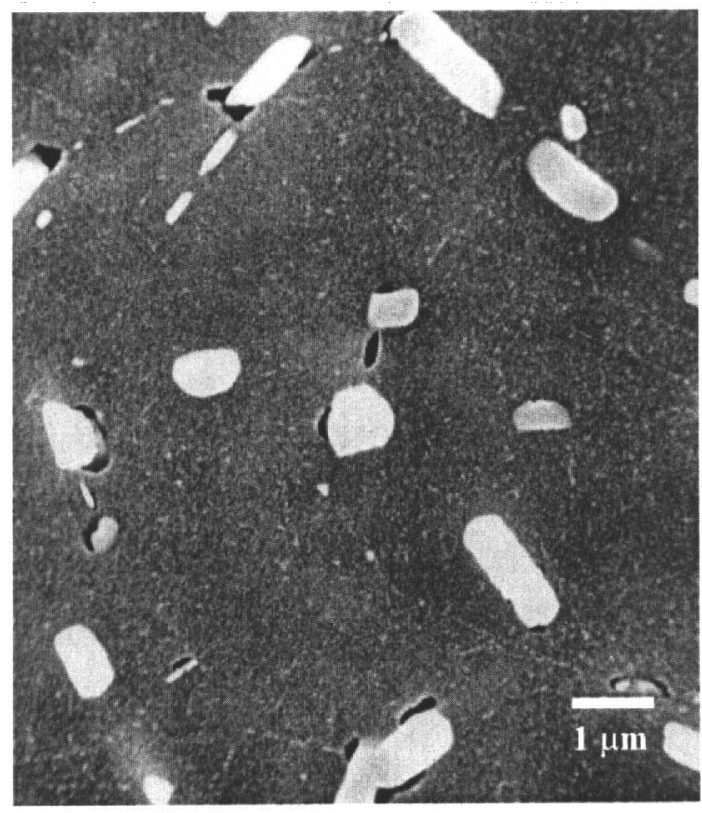

Figure 3. $1241 \mathrm{MPa}$ bolt center after a $649^{\circ} \mathrm{C}$ exposure for 500 hours.

$\mathrm{Cr}$ would be found prior to exposure. However, alpha $\mathrm{Cr}$ was found throughout all $1517 \mathrm{MPa}$ and some $1241 \mathrm{MPa}$ bolts and was associated with the delta phase. Figure 2 shows an amount of alpha $\mathrm{Cr}$ typical of most bolts, although some bolts were found to contain significantly greater amounts of alpha $\mathrm{Cr}$. No relationship between delta morphology and the amount of alpha $\mathrm{Cr}$ in the as received condition was found.

\section{Bolt Centers}

Both $1241 \mathrm{MPa}$ and $1517 \mathrm{MPa}$ bolts were then exposed at elevated temperatures for 500 hours. Figures 3 and 4 show typical microstructures from $1241 \mathrm{MPa}$ and $1517 \mathrm{MPa}$ bolts. Significantly more alpha $\mathrm{Cr}$ is found after the thermal exposure, as evidenced by the increase in holes in the 


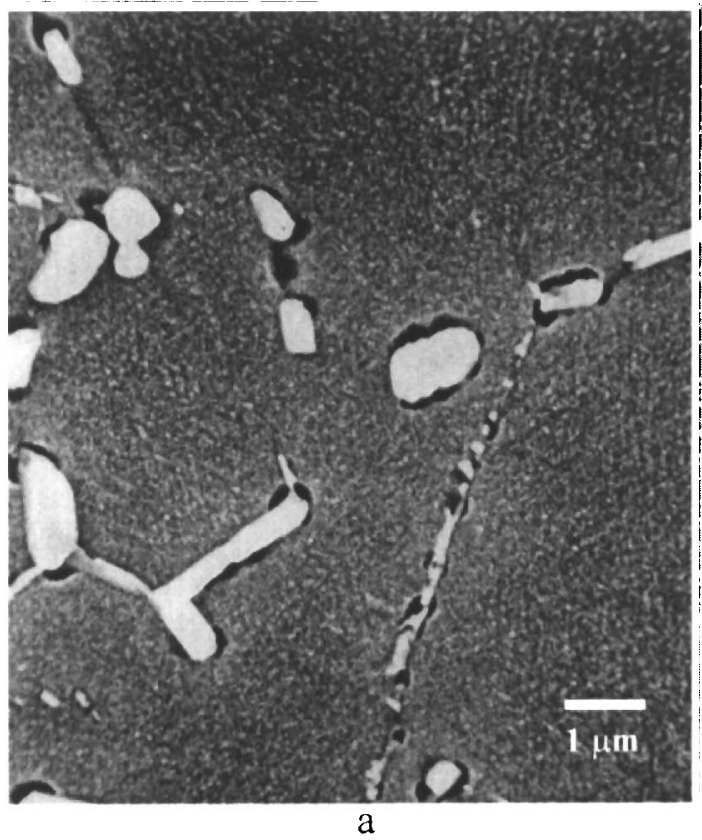

Figure 4. $1517 \mathrm{MPa}$ bolt centers exposed at (a) $677^{\circ} \mathrm{C}$ for 100 hours and (b) $649^{\circ} \mathrm{C}$ for 500

hours.

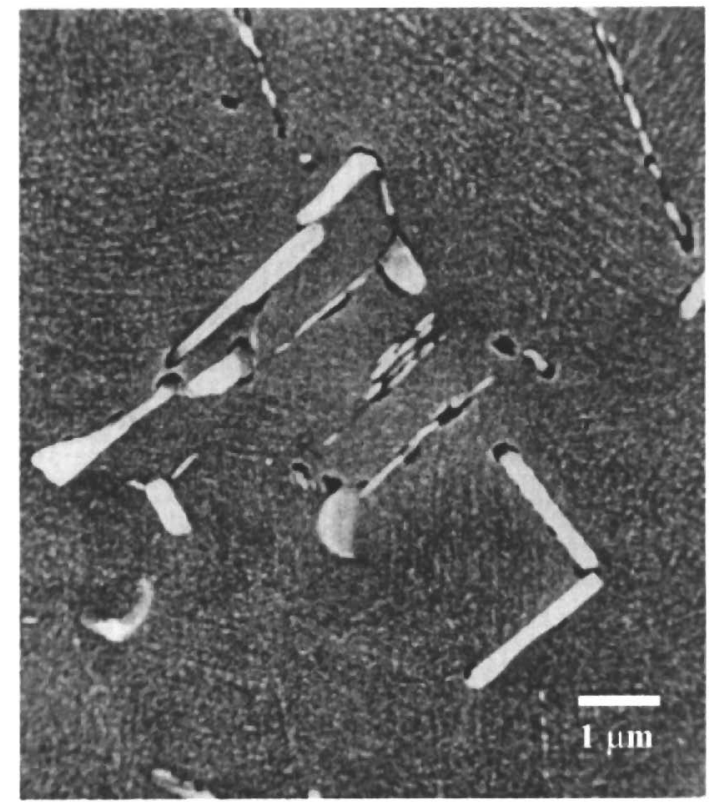

b

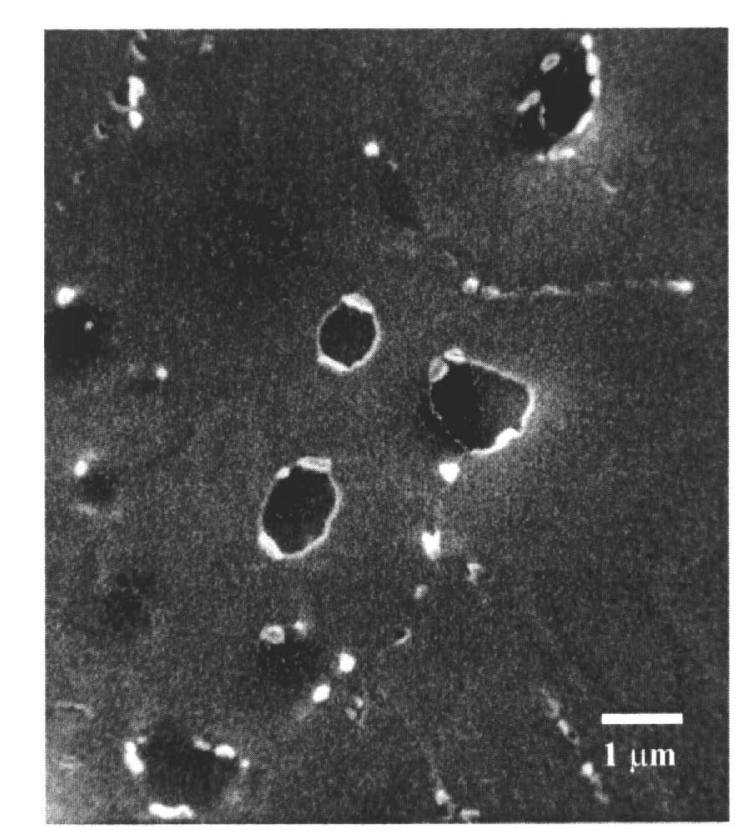

a

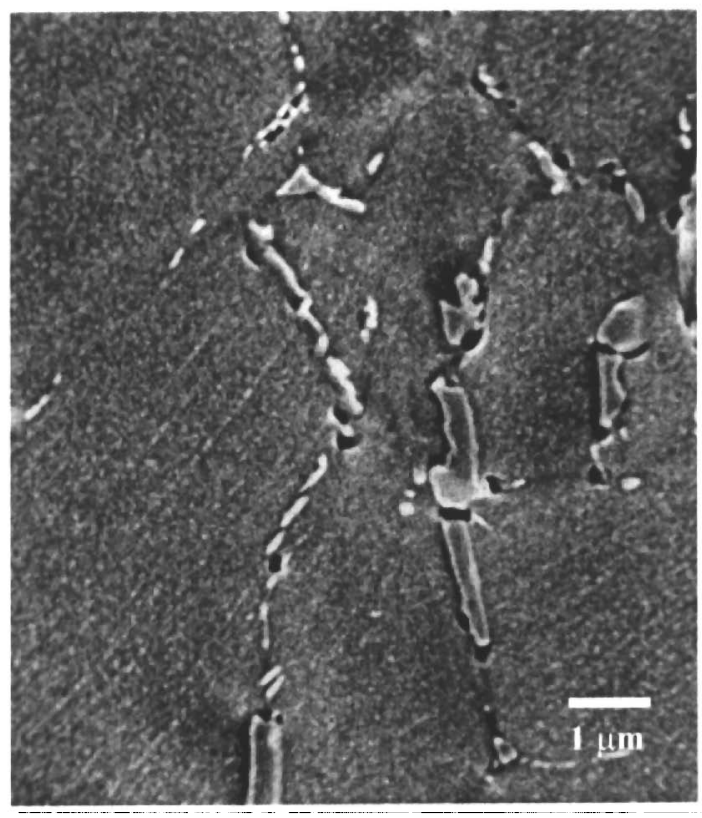

$\mathrm{b}$

Figure 5. $1517 \mathrm{MPa}$ bolt center exposed at $538^{\circ} \mathrm{C}$ for 500 hours. (a) electropolished condition (b) electroetched condition.

etched microstructures. It was found that the $20 \%$ cold work in the $1517 \mathrm{MPa}$ bolt resulted in increased amounts of alpha $\mathrm{Cr}$, Figure 4. In addition, coarsening of the $\gamma^{\prime \prime}$ can be seen in the $1517 \mathrm{MPa}$ bolts. Figure 5 shows a $1517 \mathrm{MPa}$ bolt exposed at $538^{\circ} \mathrm{C}$ for 500 hours. The alpha $\mathrm{Cr}$ can be seen in the electropolished condition and the corresponding holes are visible in the etched condition. The alpha $\mathrm{Cr}$ appears to form on both the large delta particles and on the finer grain boundary delta particles. 
A sample of $20 \%$ cold worked bar used to make $1517 \mathrm{MPa}$ bolts was obtained to understand the microstructural evolution during processing of a bolt. The bar was examined in the as-cold worked condition, and no alpha $\mathrm{Cr}$ was found (Figure 6a). A sample of the bar was then given a typical direct aging treatment of $718^{\circ} \mathrm{C}$ for 8 hours followed by $621^{\circ} \mathrm{C}$ for 8 hours. Etching of the sample revealed the presence of alpha $\mathrm{Cr}$. Subsequent tests were run to determine the time/temperature of alpha $\mathrm{Cr}$ precipitation in the $20 \% \mathrm{CW}$ bar. Figure $6 \mathrm{~b}$ shows a bar sample exposed at $718^{\circ} \mathrm{C}$ for 8 hours. Alpha $\mathrm{Cr}$ precipitation is clearly evident. Samples were also exposed at $704^{\circ} \mathrm{C}$ for 12 hours and $649^{\circ} \mathrm{C}$ for 24 hours. The alpha $\mathrm{Cr}$ precipitation quickly decreases below $704^{\circ} \mathrm{C}$, as no alpha $\mathrm{Cr}$ was found during the $649^{\circ} \mathrm{C}$ exposure.

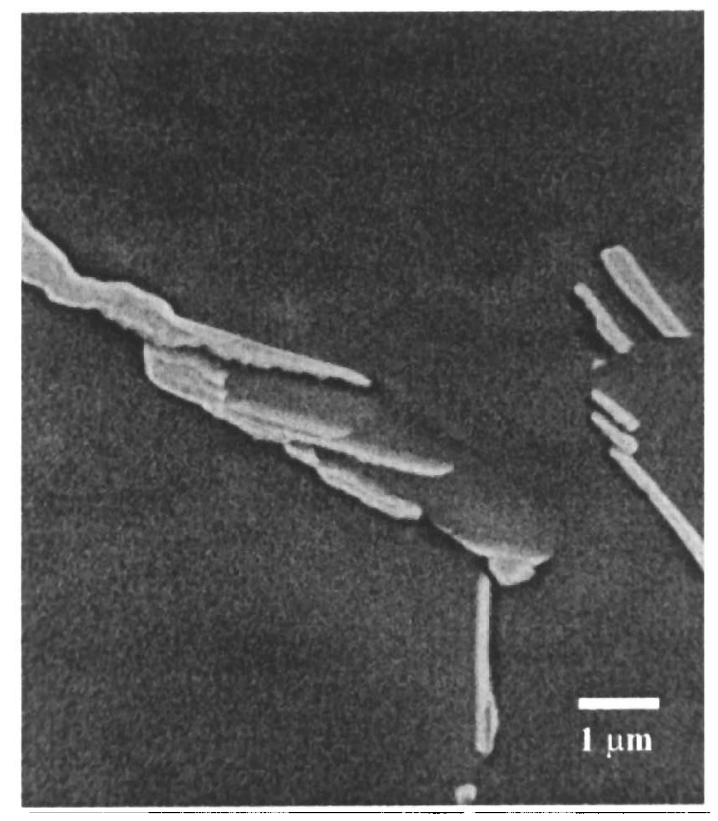

a

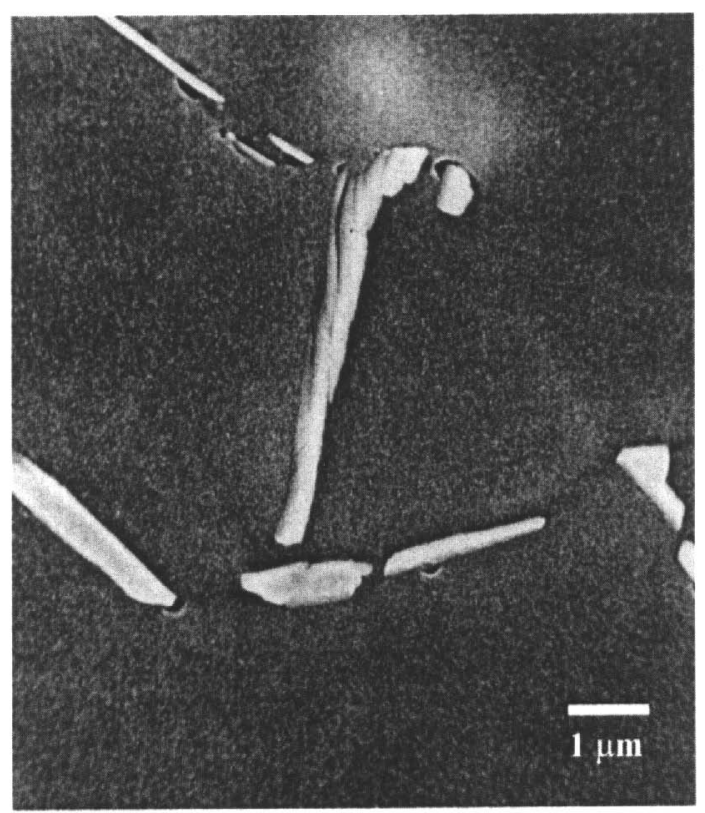

c

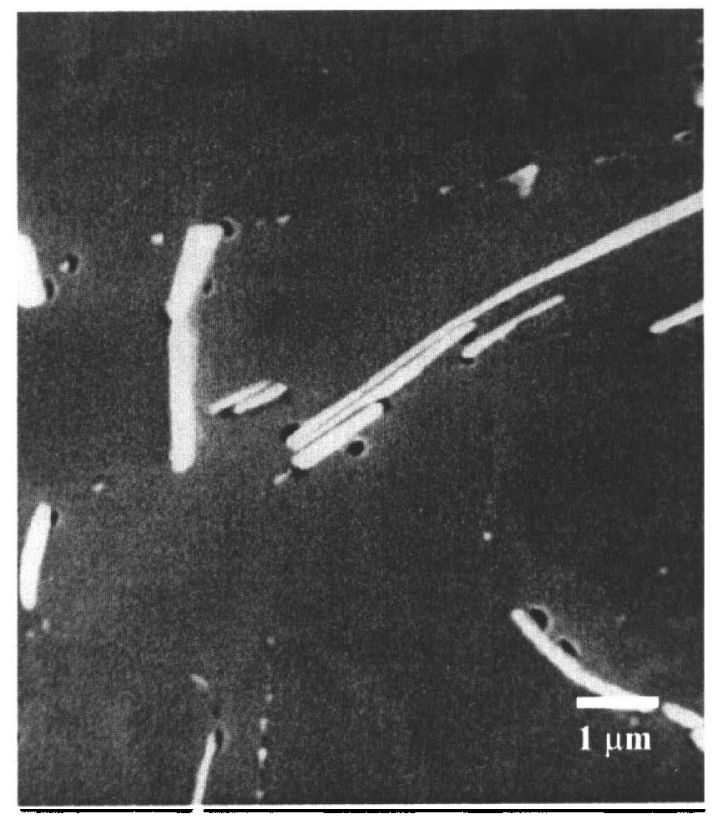

b

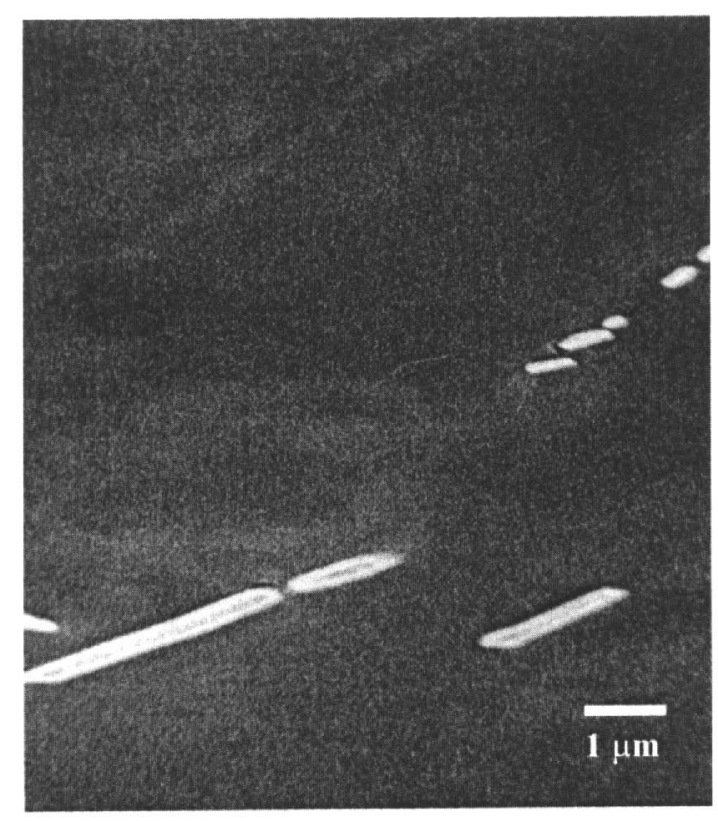

d

Figure 6. $20 \%$ cold worked bar (a) as-received and after exposure (b) $718^{\circ} \mathrm{C}$ for 8 hours, (c) $704^{\circ} \mathrm{C}$ for 12 hours and (d) $649^{\circ} \mathrm{C}$ for 24 hours. 

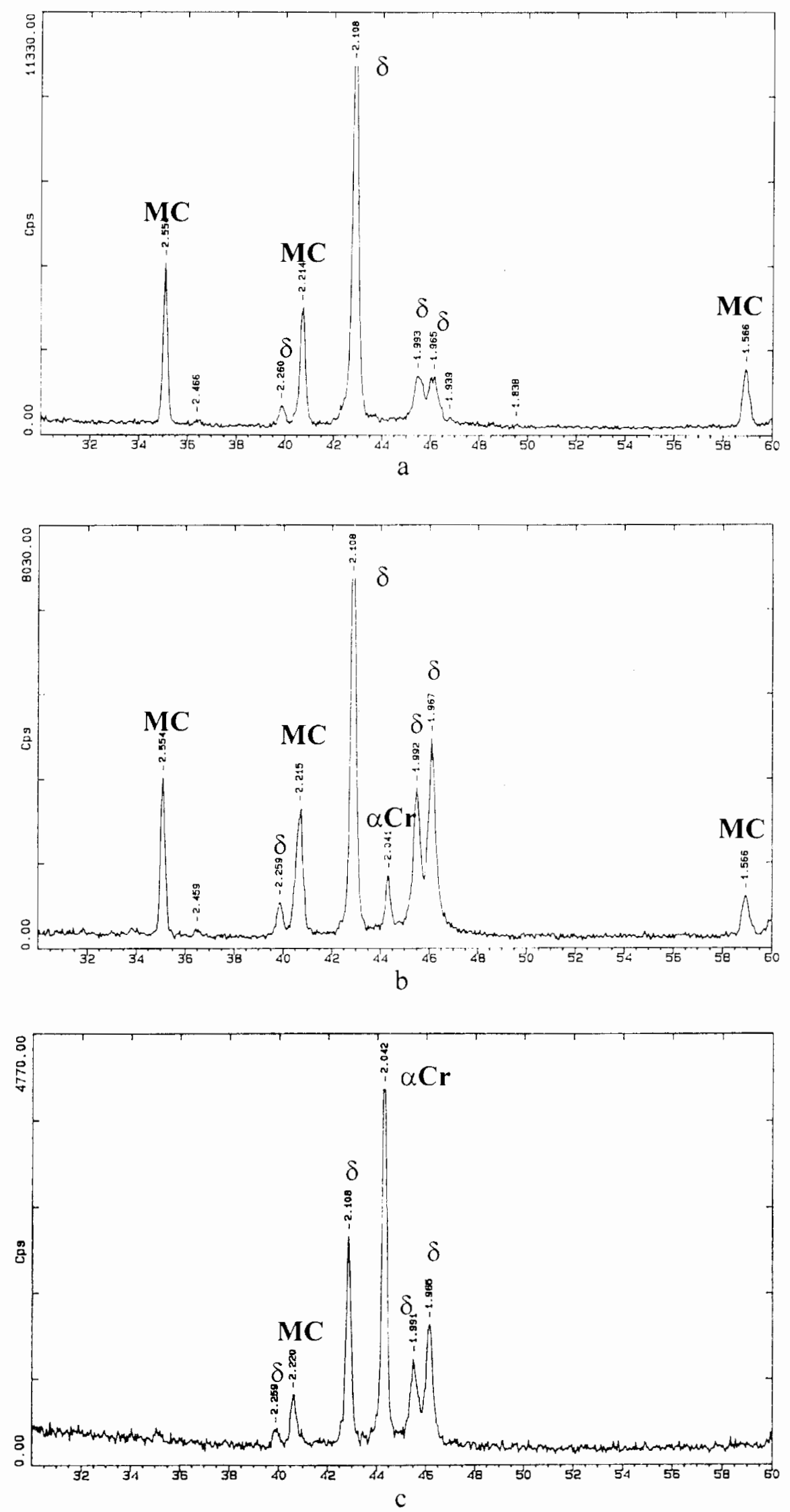

Figure 7. X-ray diffraction spectra of (a) $20 \%$ cold worked bar, (b) $20 \%$ cold worked bar plus $718^{\circ} \mathrm{C}$ for 8 hours, and (c) $1517 \mathrm{MPa}$ bolt exposed at $677^{\circ} \mathrm{C}$ for 100 hours. 
In addition to SEM evaluations, phase extractions were carried out on the as- $20 \%$ cold worked bar, a bar sample aged at $718^{\circ} \mathrm{C}$ for 8 hours, and a bolt exposed at $677^{\circ} \mathrm{C}$ for 100 hours. The $\mathrm{x}$ ray analyses of the extracted residues show that the alpha $\mathrm{Cr}$ is not present in the as-received $20 \%$ cold worked bar, but that alpha $\mathrm{Cr}$ is found after 8 hours at $718^{\circ} \mathrm{C}$. Much greater amounts of alpha $\mathrm{Cr}$ are found after a $677^{\circ} \mathrm{C}$ for 100 hour exposure, Figure 7 . The $\mathrm{x}$-ray data confirms the results found via metallography.

Since the residual strain in alloy 718 is thought to accelerate the alpha $\mathrm{Cr}$ precipitation process, two $20 \%$ cold worked bar samples, one solution treated and one as-received, were compared after aging and exposure. The first sample was solutioned at $982^{\circ} \mathrm{C}$ for 1 hour and air cooled. Both samples were then aged at $718^{\circ} \mathrm{C}$ for 8 hours and then exposed at $677^{\circ} \mathrm{C}$ for 100 hours. No difference in alpha $\mathrm{Cr}$ precipitation was found between the two samples, Figure 8 . The 1 hour solution treatment was not an effective treatment to prevent alpha $\mathrm{Cr}$. Either the solutioning step did not relieve the residual strain or perhaps the nucleation of alpha $\mathrm{Cr}$ occurred on heating or on deformation. No change in delta morphology or grain size was noted during the solution.

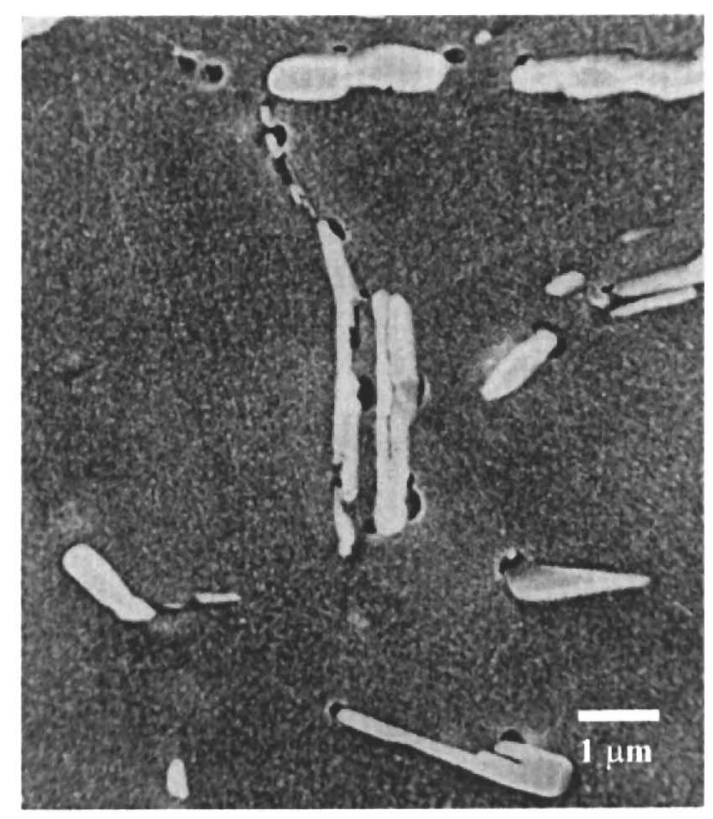

a

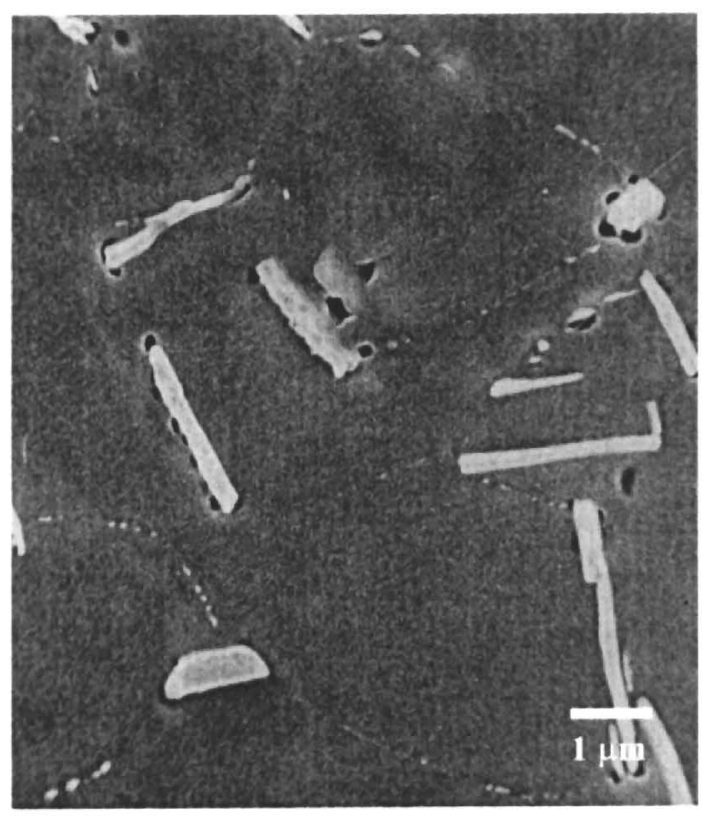

b

Figure 8. $20 \%$ cold worked bar (a) solutioned at $982^{\circ} \mathrm{C}$ for 1 hour and (b) not solutioned. Both samples were then aged at $718^{\circ} \mathrm{C}$ for 8 hours and exposed at $677^{\circ} \mathrm{C}$ for 100 hours.

\section{Bolt Threads}

As shown in an earlier section, alpha $\mathrm{Cr}$ was found associated with existing delta particles throughout the bolts and no difference in alpha $\mathrm{Cr}$ precipitation between the shank and thread regions was found. The alpha $\mathrm{Cr}$ formation in the shank portion of the bolt is a result of the original $20 \%$ cold work; however, the threads are cold rolled into the bolt after the ages and would have a higher residual strain. To study the alpha $\mathrm{Cr}$ formation in the thread areas and the shank portion, a $1241 \mathrm{MPa}$ and a $1517 \mathrm{MPa}$ bolt were exposed for 500 hours at $649^{\circ} \mathrm{C}$.

A bimodal distribution on delta was found after exposure in the threaded region of the $1241 \mathrm{MPa}$ bolt. This bimodal distribution consisted of the original larger delta precipitates and finer delta particles that precipitated during the exposure on grain and subgrain boundaries, Figure 9a. 


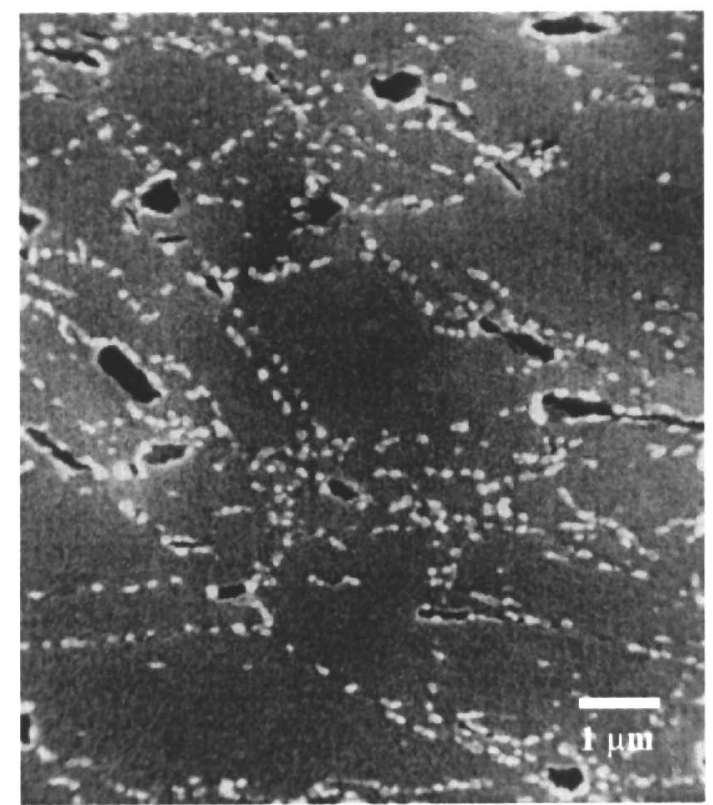

a

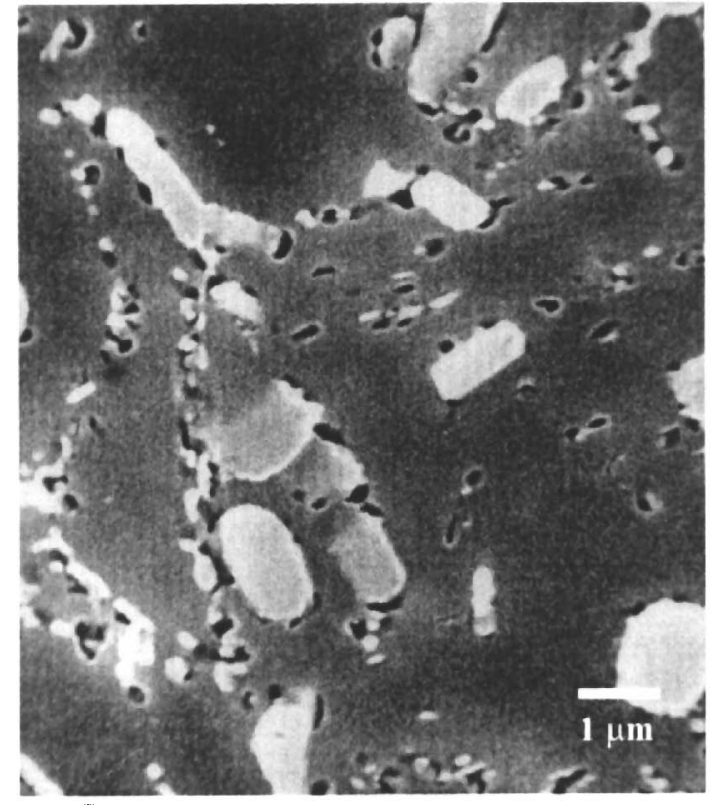

b

Figure 9. $1241 \mathrm{MPa}$ bolt thread exposed at $649^{\circ} \mathrm{C}$ for 500 hours. (a) electropolished (b) electroetched.

More significantly, large amounts of alpha $\mathrm{Cr}$ formed in this region, far surpassing the amount found in any bolt shank. The sample was re-prepared in the electropolished condition, where the delta appears dark and the alpha $\mathrm{Cr}$ white, Figure 9b. A fine distribution of alpha $\mathrm{Cr}$ formed along what appears to be network boundaries, perhaps grain or subgrain boundaries. The alpha $\mathrm{Cr}$ precipitate appears to be independent of delta phase under this severely deformed condition, although it is possible that fine delta precipitates exist that are not easily revealed with this preparation and are associated with the alpha $\mathrm{Cr}$. A similar response was found in the $1517 \mathrm{MPa}$ bolt, Figure 10, with the newly formed delta precipitates readily visible.
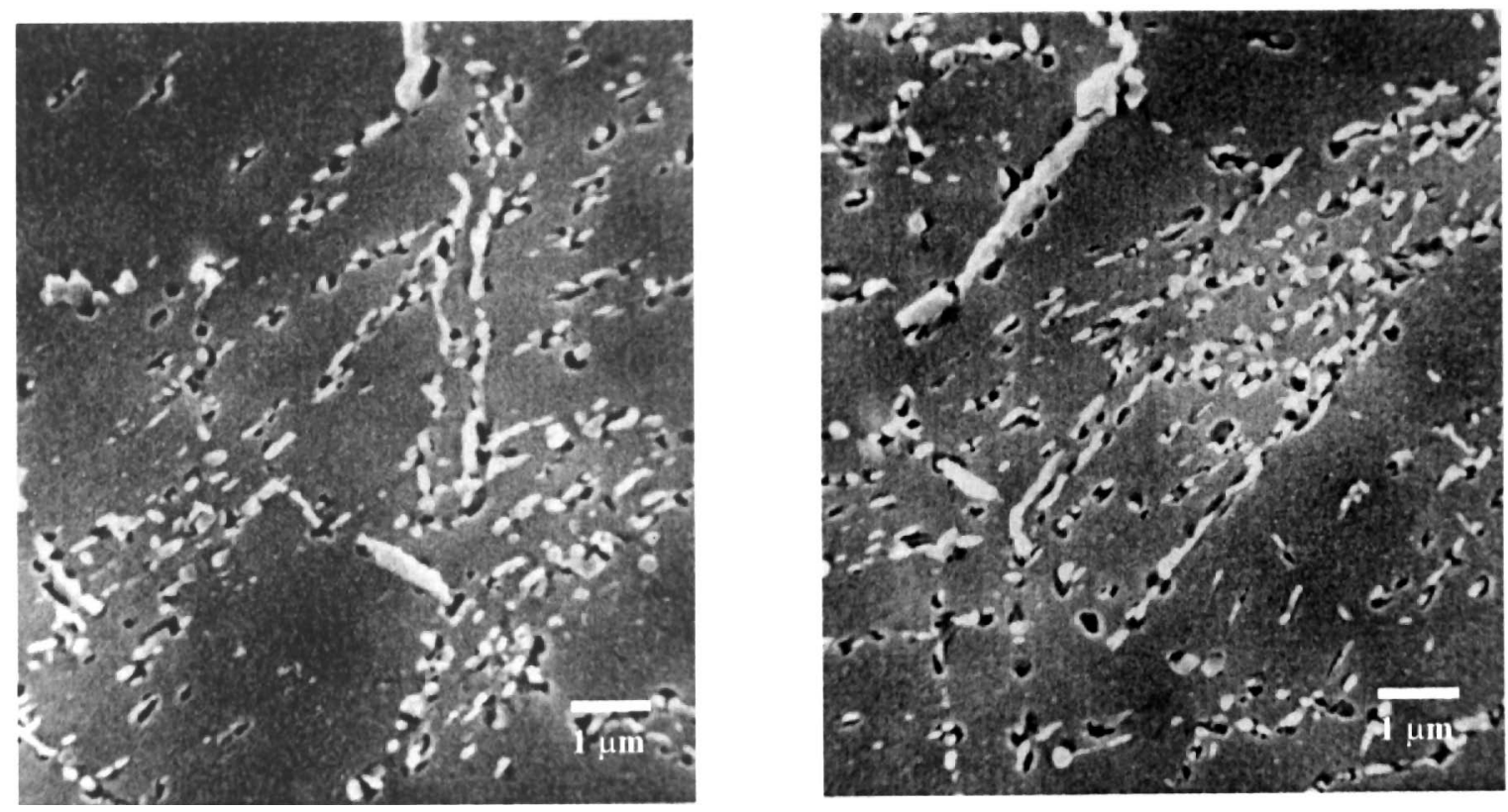

Figure 10. $1517 \mathrm{MPa}$ bolt thread exposed at $649^{\circ} \mathrm{C}$ for 500 hours. 


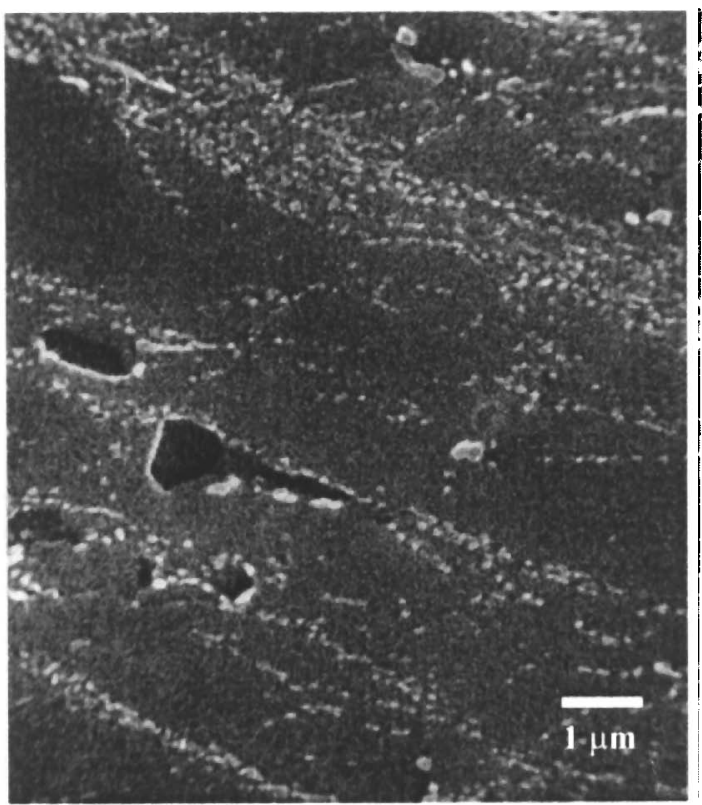

a

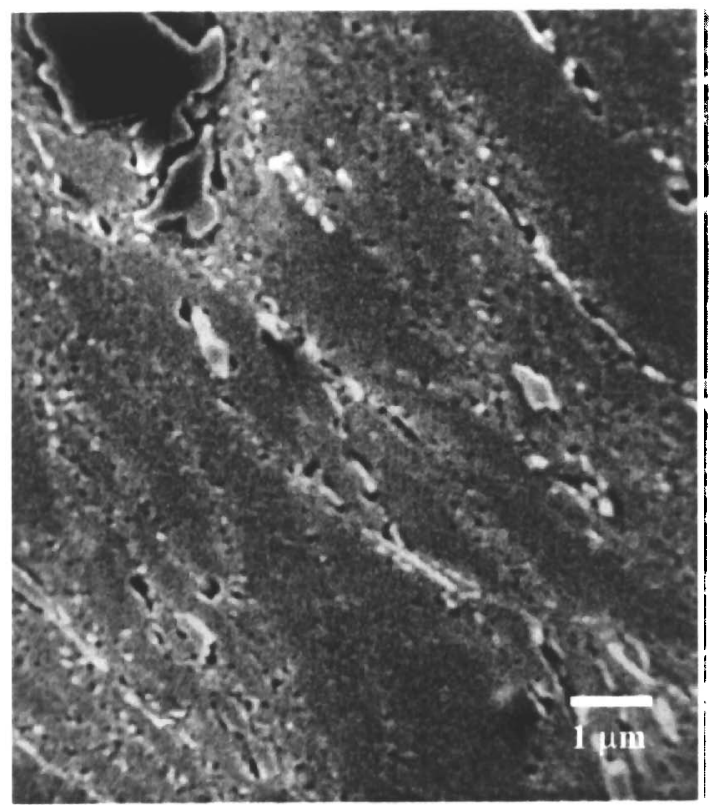

b

Figure 11. $1517 \mathrm{MPa}$ bolt thread exposed at $538^{\circ} \mathrm{C}$ for 500 hours (a) electropolished (b) electroetched.

Previous work had shown that alpha $\mathrm{Cr}$ precipitation was very sluggish at $593^{\circ} \mathrm{C}$ in solution and aged material containing low residual strain. The alpha $\mathrm{Cr}$ was detected after 25,000 hours at this temperature. To assess the effect high residual deformation on the time and temperature of alpha $\mathrm{Cr}$ precipitation, the threaded region of the bolt was examined after exposure at only $538^{\circ} \mathrm{C}$ for 500 hours. Figure 11a shows very fine alpha $\mathrm{Cr}$ precipitates clearly visible in the electropolished condition. The alpha $\mathrm{Cr}$ precipitates tend to form in aligned bands with many more nucleated particles than in the $649^{\circ} \mathrm{C}$ exposure. Very fine delta precipitates were also noted in the etched condition, Figures $11 \mathrm{~b}$.

\section{Discussion}

The amount of alpha $\mathrm{Cr}$ is determined by the amount of residual strain. $1517 \mathrm{MPa}$ bolts made from the cold worked bar had greater amounts of alpha $\mathrm{Cr}$ than the $1241 \mathrm{MPa}$ bolts. The alpha $\mathrm{Cr}$ is first nucleated in the 8 hour age at $718^{\circ} \mathrm{C}$ and continues to grow in the rest of the age cycle and during high temperature exposures. In addition, the threaded areas form greater amounts of alpha $\mathrm{Cr}$ than the bolt center during subsequent exposures due to the added strain from cold rolling in the threads.

The initial structure of bolt material reflects the processing of the material prior to bolt manufacture. Large grain bolts will be more susceptible to continuous grain boundary delta and alpha-Cr formation and thus more susceptible to embrittlement. The variations in delta morphology (discrete, spheroidal precipitates vs. plate-like, acicular precipitates) found in the bolt samples may play a role in the alpha $\mathrm{Cr}$ precipitation and material degradation, but no correlation between the different delta morphologies and alpha $\mathrm{Cr}$ precipitation was found.

The alpha $\mathrm{Cr}$ phase found in bolts is similar to that found in other wrought 718 which had been exposed at $593^{\circ} \mathrm{C}$ to $760^{\circ} \mathrm{C}$ for long times. In those studies, when copious amounts of alpha $\mathrm{Cr}$ formed, the mechanical properties were downgraded. Since alpha $\mathrm{Cr}$ has been associated with a decrease in some mechanical properties, it is expected that the extensive precipitation in the threaded region would severely degrade the mechanical properties in the area immediately 
adjacent to the threads. Large diameter bolts would be less affected by this precipitation but as the bolt diameter is decreased, the volume fraction of the affected material will increase and degrade the overall mechanical properties of the bolt.

It was interesting that the solution treatment on the $20 \%$ cold worked bar did not decrease the amount of alpha $\mathrm{Cr}$ formed after aging and exposure. It had been found that solution and aged forgings formed less alpha $\mathrm{Cr}$ than direct aged forgings (3) and it was presumed that this was due to the solution treatment. While the single test on the cold work bar does not disprove this presumption, it may be possible that some residual strain remains in the material whenever it is deformed in the presence of delta. This residual strain could persist through a solution treatment and be responsible for the accelerated alpha $\mathrm{Cr}$ precipitation. If this is true, it is advised that solution and aged $1241 \mathrm{MPa}$ bolts are not made from heavily cold worked bar.

\section{Conclusions}

1. Alpha $\mathrm{Cr}$ precipitates were found in as-received $1517 \mathrm{MPa}(220 \mathrm{ksi})$ bolts. The combination of the prior cold working of the input material and the direct aging cycle resulted in the precipitation of the alpha $\mathrm{Cr}$.

2. Aging of $20 \%$ cold worked bar revealed that alpha $\mathrm{Cr}$ readily precipitated at $718^{\circ} \mathrm{C}$ while significantly less was found at lower temperature and longer times. Solutioning the cold worked bar at $982^{\circ} \mathrm{C}$ did not affect the precipitation of alpha $\mathrm{Cr}$ after aging and exposure.

3. After long term exposure at elevated temperature, more alpha $\mathrm{Cr}$ was found in $1517 \mathrm{MPa}$ $(220 \mathrm{ksi})$ bolts than $1241 \mathrm{MPa}(180 \mathrm{ksi})$ bolts due to increased residual strain.

4. Severe alpha $\mathrm{Cr}$ precipitation was found in the material adjacent to the bolt threads at temperatures as low as $538^{\circ} \mathrm{C}$. Precipitation occurred on a network of what appeared to be grain or subgrain boundaries.

\section{References}

1. T. A. Roach, "Alloy 718 fasteners : versatility and reliability for aerospace design", Superalloy 718 - Metallurgy and Applications, E. A. Loria (Seven Springs, PA: TMS, 1989), 381-389.

2. J. F. Radavich and G. E. Korth, "High temperature degregation of alloy 718 after longtime exposures", Superalloys 1992, S. D. Antolovich, et al. (Seven Springs, PA: TMS, 1992), 497506.

3. G. Shen, et al., "The effects of processing on stability of alloy 718", Superalloys 2000, T. M. Pollock, et al. (Seven Springs, PA: TMS, 2000), 445-448.

4. B. Lindsley, et al., "Alpha $\mathrm{Cr}$ formation in alloy 718 during long term exposure : the effects of chemistry and deformation", Long Term Stability of High Temperature Materials, G. E. Fuchs, et al. (Warrendale, PA: TMS, 1999), 123-133. 